\title{
Nuclear Factor of Activated T Cells 5 Deficiency Increases the Severity of Neuronal Cell Death in Ischemic Injury
}

\author{
Keri Man Chi Mak ${ }^{\mathrm{a}}$ Amy Cheuk Yin Lo ${ }^{\mathrm{a}, \mathrm{b}}$ Amy Ka Man Lam ${ }^{\mathrm{a}}$ \\ Patrick Ka Kit Yeung ${ }^{c}$ Ben Chi Bun Ko ${ }^{c}$ Stephen Sum Man Chung ${ }^{d}$ \\ Sookja Kim Chunga, b \\ ${ }^{a}$ Department of Anatomy, Li Ka Shing Faculty of Medicine, ${ }^{b}$ Research Center of Heart, Brain, Hormone and Healthy \\ Aging, and ' Department of Anatomical and Cellular Pathology, Chinese University of Hong Kong, Hong Kong, SAR, \\ China; ${ }^{\mathrm{d} D i v i s i o n}$ of Science and Technology, United International College, Zhuhai, China
}

\section{Key Words}

NFAT5 $\cdot$ Ischemia $\cdot$ SMIT $\cdot$ Oxidative stress $\cdot$ Knockout

\begin{abstract}
Nuclear factor of activated T cells 5 (NFAT5) has been implicated in regulating several genes that are thought to be neuroprotective in ischemic injury. Because of the embryonic lethality of NFAT5 knockout (NFAT5 ${ }^{-/}$) mice, the heterozygous (NFAT5 ${ }^{+/-}$) mice were used to study the in vivo role of NFAT5 in hypoxia/ischemia (H/I) condition. The NFAT5 ${ }^{+/-}$ mice exhibited more severe neurological deficits, larger infarct area and edema formation associated with increased aquaporin 4 expressions in the brain. Under in vitro $\mathrm{H} / \mathrm{I}$ condition, increased apoptotic cell death was found in NFAT5 ${ }^{-/}$ neurons. Moreover, SMIT, a downstream to NFAT5, was upregulated in $\mathrm{NFAT5}^{+/+}$neurons, while the SMIT level could not be upregulated in $\mathrm{NFAT5}^{-/-}$neurons under $\mathrm{H} / \mathrm{I}$ condition. The elevation of reactive oxygen species generation in NFAT5 ${ }^{-/-}$neurons under $\mathrm{H} / \mathrm{I}$ condition further confirmed that $\mathrm{NFAT5}^{-/-}$neurons were more susceptible to oxidative stress. The present study demonstrated that activation of NFAT5 and its downstream SMIT induction is important in protecting neurons from ischemia-induced oxidative stress.
\end{abstract}

\section{KARGER}

Fax +4161306 1234

E-Mail karger@karger.ch

www.karger.com
(C) 2012 S. Karger AG, Basel

1424-862X/12/0204-0237\$38.00/0

Accessible online at:

www.karger.com/nsg

\section{Introduction}

Maintaining brain cells in ionic and osmotic balance is essential for the proper function of the central nervous system. Brain interstitial and cerebrospinal fluids are in osmotic equilibrium with blood plasma. The blood plasma osmolality is tightly maintained under normal physiological conditions. In addition, a rigid skull limits the expansion of brain tissues, since the changes in total brain cell volume can result in detrimental neurological disorders [1-3]. Changes in brain tissue or CSF osmolality after cerebral ischemia are documented $[4,5]$. Similar to the osmotic adaptation in renal epithelial cells, brain cells possess osmoprotective mechanisms and enable them to adapt the changes in cell volume [6-8]. When animals were subjected to systemic hypertonicity, the mRNA levels of osmoprotective genes were induced in brains [9], and the water content of brain tissue restored back to normal level [10]. The transcriptions of osmoprotective genes are thought to be primarily under the control of nuclear factor of activated T cells (NFAT) 5 which is also known as osmotic responsive element binding protein (OREBP) or tonicity-responsive enhancer binding protein (tonEBP) [11].

NFAT5, a transcription factor, belongs to the Rel family. Although NFAT5 has similar protein structures to 
other members of the Rel family, the biological functions are quite different from the others. NFAT5 is involved in cellular adaptation to hypertonicity by activating osmoprotective genes transcription, such as transporters and enzyme for accumulating organic osmolytes: sodium/myo-inositol cotransporter (SMIT), the sodium-chloride-betaine cotransporter (BGT1), taurine transporter (TauT) and aldose reductase (AR) [12]. NFAT5 is also involved in stress-related gene transcription, such as heat shock protein 70 (HSP70), which is known to contain osmotic response element (ORE), and is regulated by NFAT5 under hypertonic stress [13].

In ischemia, a number of genes are actively transcribed and translated. An antiapoptotic protein, HSP70, has been reported to protect the brains from H/I injury [14]. Besides, AR is an enzyme in the polyol pathway and is upregulated during cerebral ischemia, AR deletion protects the brains from ischemic injury [15]. Moreover, the expression of SMIT mRNA increases significantly in the ischemic core after focal cerebral ischemia [16]. The release of taurine, through the taurine transporters, in neurons is neuroprotective during cerebral ischemia [17].

Cerebral ischemia causes extensive osmotic stress in the brain. Similar to renal cells, osmoregulatory mechanism is also found in the brain cells against the osmotic stress [6-8]. NFAT5 expression is primarily found in the neurons of the rat brains [18] and it is, therefore, possible that NFAT5 may play an important role in regulating the transcription of its target genes in response to and cope with the ischemic injury. In the present study, the biological function of NFAT5 in H/I injury was studied by using NFAT5 heterozygous knockout $\left(\mathrm{NFAT}^{+/-}\right)$mice. The NFAT ${ }^{+/-}$mice were subjected to transient middle cerebral artery occlusion (tMCAO). They exhibited more severe neurological deficits, larger infarct and cerebral edema with increased blood brain barrier breakdown and aquaporin- 4 expression. In the in vitro study using NFAT5 knockout neurons, we have demonstrated that H/I injury led to activation of NFAT5 resulting in increased NFAT5 protein synthesis, nuclear translocation and transcription activity in the neurons. All of these cellular processes were involved in neuronal protection against ischemic injury. The NFAT5-dependent transcription of ischemic-related genes, such as AR, SMIT, TAUT and HSP70 was also studied by real-time PCR. The increased mRNA expression of SMIT after 3-h H/I was observed in the $\mathrm{NFAT}^{+/+}$neurons but not in the $\mathrm{NFAT5}^{-/-}$neurons. The $\mathrm{NFAT5}^{-/-}$neurons were under more severe oxidative stress when compared with $\mathrm{NFAT}^{+/+}$neurons after $\mathrm{H} / \mathrm{I}$ insult. Taken together,
NFAT5 is not only important in protecting neuronal cells from osmotic stress during the hypertonic condition, but it also plays a protective role by regulating the cytoprotective SMIT expression in response to ischemic environment.

\section{Materials and Methods}

Mice were housed under diurnal lighting condition and allowed free access to food and water. The protocol of this study was reviewed and approved by the Committee on the Use of Live Animals in Teaching and Research in The University of Hong Kong.

\section{Generation of NFAT5 ${ }^{-/}$Mice}

The mouse nfat 5 gene was inactivated by partially replacing the region of nuclear localization sequence and DNA-binding domain within the exon 5 and exon 6 with neomycin-resistance cassette in embryonic stem (ES) cells. Homologous recombination integrated the targeting construct into nfat 5 locus. The gene-targeted nfat $5^{+/-}$ ES cells were verified by using polymerase chain reaction (PCR) and Southern blot analysis. Injection of gene-targeted ES cells into the blastocytes from C57BL/6N mice generated chimeric founder that transmitted the mutated allele into the germline. To generate $\mathrm{NFAT5}^{-/}$embryos, mice heterozygous for the NFAT5 alleles $\left(\mathrm{NFAT}^{+/-}\right)$on SVJ129/C57BL/6N background was intercrossed [19], and the morning vaginal plug examination was designated as embryonic day 0.5 (E0.5d). The NFAT5 knockout allele was identified by PCR amplification using PCR primers, p3: 5'-AGGCACACAGTCTTGTACATCTCAC-3'; p3RA: 5'-CC-TCTATGCCTAACCATACATAA-3' and pA: 5'-GATCAGCAGCCTCTGTTCCA$3^{\prime}$, with denaturing temperature $95^{\circ} \mathrm{C}, 1 \mathrm{~min}$; annealing temperature $60^{\circ} \mathrm{C}, 1 \mathrm{~min}$; extension temperature $72^{\circ} \mathrm{C}, 1 \mathrm{~min}$.

\section{RT-PCR Analysis}

RT-PCR analysis was performed using total RNA isolated from brain tissues from various genotype mice. NFAT5 primers (5'-CAC CAC CAC CTG AGG ACT TGC TG-3' and 5'-TTC ACA ATC TCG TCG TTT GAC CCC-3') recognize a fragment of NFAT 5 mRNA. $3 \mu \mathrm{g}$ of total RNA dissolved in $10 \mu$ l DEPC-treated water was hybridized to $1 \mu \mathrm{l}$ random hexamer $(50 \mathrm{mM})$ for 10 $\min$ at $70^{\circ} \mathrm{C}$. The hybridized RNA-hexamer was used to generate cDNA using Superscript ${ }^{\mathrm{TM}}$ II RNase H-reverse transcriptase.

\section{Western Blot Analysis}

Proteins were isolated brain tissues and homogenized in lysis buffer (50 mmol/l Tris-HCl, pH 6.8, $150 \mathrm{mmol} / \mathrm{l} \mathrm{NaCl}, 5 \mathrm{mmol} / \mathrm{l}$ EDTA, $0.5 \%$ sodium deoxycholate, $0.5 \% \mathrm{NP}-40$ plus protease inhibitor cocktail) [20]. Homogenate was centrifuged at 3,000 $\mathrm{g}$ for $5 \mathrm{~min}$ at $4^{\circ} \mathrm{C}$. Blots were incubated with antibodies against NFAT5 (1:400, a kind gift from Prof. H.M. Kown, University of Maryland) and $\alpha$-tubulin (1:5,000, sc-5286, Santa Cruz, Calif., USA). Signals were visualized by ECL (Amersham) and quantitated by using PhosphoImager (Molecular Dynamics).

Transient Focal Cerebral Ischemia

Transient focal cerebral ischemia was induced by intraluminal occlusion of the right middle cerebral artery as previously 
described [20-23]. Age-matched littermates of $\mathrm{NFAT}^{+/+}$and $\mathrm{NFAT}^{+/-}$adult mice (8-12 weeks old) were subjected to tMCAO by the filament method. Briefly, a nylon monofilament (Johnson and Johnson, Brussels, Belgium) coated with impression material ( 3 M; Dental Products, St. Paul, Minn., USA) was inserted into right internal carotid artery to block the origin of right middle cerebral artery. Regional cerebral blood flow (rCBF) was monitored during the whole surgical procedure to confirm appropriate suture placement while rectal temperature was maintained at $37^{\circ} \mathrm{C} \pm 0.5^{\circ} \mathrm{C}$ with a temperature control system (FHC, Brunswick, Me., USA). After $2 \mathrm{~h}$ of occlusion, the filament was pulled out to allow reperfusion for $22 \mathrm{~h}$ and the mouse was kept in an intensive care system (ThermoCare Inc., Incline Village, Nev., USA) at $32^{\circ} \mathrm{C}$ for $4 \mathrm{~h}$ before transferred back to home cage. After $22 \mathrm{~h}$ of reperfusion, neurological deficits evaluations were performed before brains were collected for further analysis. Mice were evaluated for neurologic deficits [20] as follows: (0) no observable neurologic deficits (normal); (1) failure to extend opposite forepaw (mild); (2) circling to the contralateral side (moderate); (3) loss of walking and righting reflex (severe). The person did the rating was naive to the animal identity and to the treatment protocol.

\section{Brain Infarct Analysis}

The brain was collected after tMCAO and sectioned into six 2-mm-thick slices coronally. The brain slices were stained with 2\% 2,3,5-triphenyltetrazolium chloride (TTC, Sigma, St. Louis, Mo., USA) in the dark at $37^{\circ} \mathrm{C}$ for $10-15 \mathrm{~min}$. The posterior surface of each slice was photographed and analyzed by image analysis program (Sigma Scan Pro 5.0, Statistic Package for the Social Sciences: SPSS Inc.). Infarct area and volume percentages were calculated using an indirect method and presented as the percentage of infarct area of the contralateral hemisphere to eliminate the contribution of edema to the ischemic lesion [20]. The hemispheric brain swelling was assessed as the increase in volume in ipsilateral hemisphere relative to the contralateral volume expressed in a percentage manner [20].

\section{Immunocytochemical (ICC) Analysis of Brain Tissue}

After tMCAO, brain samples were collected after $24 \mathrm{~h} .7-\mu \mathrm{m}$ paraffin-embedded tMCAO-treated brain sections were fixed with $4 \%$ paraformaldehyde and stained with antibodies against NFAT5 (1:500, a kind gift from Prof. H.M. Kown, University of Maryland), Occludin (1:50, Santa Cruz) and AQP-4 (1:200, Chemicon International). For IgG immunostaining, sections were incubated with biotinylated goat anti-mouse IgG (1:200 dilution; Vector Laboratories, Inc., USA). Signals were visualized by Vectastain ABC kit (Vector Laboratories, Burlingame, Calif., USA) with 3,3'diaminobenzidine tetrahydrochloride (Zymed, South San Francisco, Calif., USA). Photomicrographs were taken with a Zeiss Axiophot microscope. For controls, primary antibodies were omitted on adjacent sections.

\section{Quantification of Blood-Brain Barrier (BBB) Breakdown}

Quantification of the BBB data was performed by quantification of the IgG contra- and ipsilateral of $\mathrm{NFAT}^{+/+}$and $\mathrm{NFAT5}^{+/-}$ brain sections. Photomicrograph (magnified $\times 20$ ) of brain sections with IgG leakage were analyzed with Image J software, which allowed us to measure the degree of the IgG leakage, and therefore, the integrity of the BBB.

\section{Cell Culture}

SH-S5Y5 neuroblastoma cells (a kind gift from Dr. M.W. Cheung from CUHK) were cultured in MEM and DMEM-F12 supplemented with $10 \%$ fetal bovine serum, glutamine, penicillin and streptomycin. To obtain mouse embryonic primary cortical neurons, $\mathrm{NFAT5}^{+/-}$mice male and female were intercrossed. Primary neurons were cultured in neurobasal medium supplemented with B-27, glutamine, penicillin and streptomycin. After 5 days, the neuronal culture was subjected to $100 \mu \mathrm{M} \mathrm{H}_{2} \mathrm{O}_{2}$ or to in vitro $\mathrm{H} / \mathrm{I}$ for $3 \mathrm{~h}$ (anaerobic chamber, Thermalfisher).

\section{Luciferase-Activity Measurement}

The SH-S5Y5 cells were co-transfected with $600 \mathrm{ng}$ of ORE-Luc and $300 \mathrm{ng}$ of phRG-TK. For the control, the cells were co-transfected with $600 \mathrm{ng}$ of pGL3 and $300 \mathrm{ng}$ of phRG-TK. Transfection was carried out using FuGENE 6 according to the manufacturer's instructions. $24 \mathrm{~h}$ after transfection, the cells were subjected to in vitro $\mathrm{H} / \mathrm{I}$. In vitro $\mathrm{H} / \mathrm{I}$ was induced in neuronal cultures by subjecting cultures to hypoxia in an anaerobic chamber (Forma Scientific, Ohio, USA) that preconditioned with $5 \% \mathrm{CO}_{2} / 85 \% \mathrm{~N}_{2} / 10 \% \mathrm{H}_{2}$ and glucose-free conditions for 0,1 and $3 \mathrm{~h}$. The $\mathrm{O}_{2}$ content in the chamber was measured by an oxygen electrode (Microelectrodes, Inc., Nashua, N.H., USA), and less than $10 \mathrm{ppm} \mathrm{O}_{2}$ was detected. The ORE activity was measured by luciferase report assay. After $\mathrm{H} / \mathrm{I}$ treatment, cells were lysed with $500 \mu \mathrm{l}$ of passive lysis buffer and luciferase activity was determined by using dual luciferase reporter assay system. $100 \mu \mathrm{l}$ of luciferase assay reagent II (LAR II) was added into a luminometer tube. Then, $20 \mu \mathrm{l}$ of cell lysate was added into the luminometer tube and mixed by pipetting. The tube was plated in the luminometer. The firefly luciferase activity was recorded. $100 \mu \mathrm{l}$ of Stop and Glo Reagent was added and mixed. The Renilla luciferase activity was recorded. The luciferase activity was normalized by Renilla luciferase activity.

\section{Immunocytochemical Analysis of Primary Cultured Neurons}

The primary neuronal cells were plated onto a coverslip in a 12 -well plate. After 5 days of incubation, the cells were treated with in vitro H/I. The medium was aspirated and the cells were washed twice with $1 \times$ PBS. The cells were fixed with $4 \%$ paraformaldehyde for $15 \mathrm{~min}$ at room temperature and washed three times with $1 \times$ PBS. The cells then were laid with methanol for 2 min and washed with $1 \times$ PBS three times. The sample was blocked by $3 \%$ BSA for $1 \mathrm{~h}$ and then incubated with rabbit antiNFAT5 antibody $(1: 4,000)$ for $2 \mathrm{~h}$. Then, the cells were washed three times with $1 \times$ PBS with each time for 5 min at room temperature and incubated with FITC-conjugated secondary antibody. After $1 \mathrm{~h}$ of incubation, the cells were stained with DAPI for 5 min. Then, the cells were washed three times with $1 \times$ PBS for 5 min, air-dried and mounted in Fluorsave ${ }^{\mathrm{TM}}$ reagent.

\section{Lactate Dehydrogenase Measurement}

To detect the ischemia-induced cytotoxicity on the primary cultures of $\mathrm{NFAT}^{+/+}, \mathrm{NFAT}^{+/-}$and $\mathrm{NFAT}^{-/-}$neuronal cells, lactate dehydrogenase ( $\mathrm{LDH}$ ) assay kit was used. $3 \mathrm{~h}$ after $\mathrm{H} / \mathrm{I}$ treatment, $100 \mu \mathrm{l}$ of medium was removed from the culture dish and added to 96 -well plate. $100 \mu \mathrm{l}$ of the reaction mixture from the $\mathrm{LDH}$ kit was added to each sample. The plate was then incubated for $30 \mathrm{~min}$ at room temperature in the dark. The spectrophotometrical absorbance of the samples was measured using a microtiter plate (ELISA) reader. The absorbance wavelength for the 
formazan product is $492 \mathrm{~nm}$ and the background absorbance wavelength is $690 \mathrm{~nm}$. The amount of LDH release was defined as the ratio of $\mathrm{LDH}$ activity in the medium to the $\mathrm{LDH}$ activity observed after total cell death according to the manufacturer's protocol and was expressed as percentage of total LDH activity.

\section{Terminal Deoxynucleotidyl Transferase Biotin-dUTP Nick}

End Labeling (TUNEL) Staining

The neuronal cells were plated onto a coverslip in a 12-well plate. After 5 days of incubation, the cells were subjected to in vitro $\mathrm{H} / \mathrm{I}$. The medium was aspirated and the cells were washed twice with $1 \times$ PBS. The cells were fixed with $4 \%$ paraformaldehyde for $1 \mathrm{~h}$ at room temperature and washed with $1 \times$ PBS three times. The cells were incubated with blocking for $10 \mathrm{~min}$ at room temperature and washed with $1 \times$ PBS three times. The cells then were permeabilized in methanol for $2 \mathrm{~min}$ on ice and washed twice with $1 \times$ PBS. $50 \mu$ l of TUNEL reaction mixture was added on the samples and incubated for $60 \mathrm{~min}$ at $37^{\circ} \mathrm{C}$ in a humidified atmosphere in the dark. The samples were counterstained with DAPI for 5 min at room temperature, and washed three times with $1 \times$ PBS for $5 \mathrm{~min}$, air-dried and mounted in Fluorsave $\mathrm{T}^{\mathrm{TM}}$ reagent.

\section{Sample Preparation, RNA Isolation, cDNA Preparation and} Real-Time PCR for Measurement of Abundance of Specific RNAs

Total RNA was isolated from primary cortical neurons and brain slices. DNase treatment was performed to minimize contamination by genomic DNA. cDNA was prepared with TaqMan reverse transcription reagents using random hexamers according to the manufacturer's instructions (Applied Biosystems). cDNA was quantified with ABI Prism 7900HT sequence detection system (Applied Biosystems). The accumulation of the PCR product was monitored in real time by a fluorogenic $5^{\prime}$-nuclease assay, using probes specific for each cDNA being tested. Primers and probes were designed from mouse cDNA sequences. The PCR primers were designed to span a sequence of genes that contains introns, namely SMIT (Mm00444330_s1, Applied Biosystems), TauT (Mm00436909_m1, Applied Biosystmes), 18S rRNA primers and $18 \mathrm{~S}$ probes (Applied Biosystems), AR and HSP70-2 [24].

\section{Analysis of Real-Time PCR Data}

The results were analyzed using ABI Prism 7900 system software (Applied Biosystems). Relative mRNA abundance was calculated from the real-time PCR data using the following principles. (1) By definition the number of specific cDNA molecules at the threshold $\left(\mathrm{N}_{\mathrm{Ct}}\right)$ is constant for a given cDNA, independent of the number of cycles that it takes to reach it. (2) For a specific cDNA the ratio $\mathrm{N}(\exp )_{\mathrm{i}} / \mathrm{N}(\mathrm{cont})_{\mathrm{i}}$ is independent of $\mathrm{i}$, assuming only that the efficiency (E) of PCR for a specific template is constant, where $i$ is the cycle number, and $N(X)_{i}$ is the number of specific cDNA molecules in a sample $(\mathrm{X}=$ control or experimental) at cycle i. (3) The ratio of the number of specific cDNA molecules at a cycle, $\mathrm{Ct}$, to the number at another cycle, i, is $\mathrm{Ni} / \mathrm{N}_{\mathrm{Ct}}=1$ / $\mathrm{E}^{(\mathrm{Ct}-\mathrm{i})}$. The control and experimental results were compared. The number of specific molecules at an arbitrary cycle was normalized, I, chosen for convenience to be the largest whole number that was less than any of the experimental values of $\mathrm{Ct}$. Then, Ni/N $\mathrm{N}_{\mathrm{Ct}}$ for each sample was calculated. Experimental results were presented as the relative amount of the corresponding control value.

\section{Measurement of Intracellular ROS Generation}

Intracellular oxidative stress was monitored by measuring the changes of fluorescence resulting from intracellular probe oxidation. The probe 2',7'-dichlorofluorescin (DCFH-DA, $10 \mu \mathrm{M}$; Molecular Probes) is a non-polar compound and readily diffuses into cells. It can be oxidized by ROS and yields the fluorescent product. Thus, increases in DCFH to DCF are suggestive of ROS generation. Neuronal cultures after different $\mathrm{H} / \mathrm{I}$ treatments were incubated with the probe in the dark for $30 \mathrm{~min}$ before viewed under fluorescent microscope. Culture dishes were viewed on a Zeiss Axiovert 135 inverted confocal microscope equipped with a $\times 20$ Neofluor objective and Zeiss LSM 410 confocal attachment (Carl Zeiss, Minneapolis, Minn., USA). DCF fluorescence was measured at an excitation wavelength of $488 \mathrm{~nm}$ and emission at 515-540 nm. At least five fields of each dish were randomly selected and the fluorescence intensity value was measured (Karl Zeiss vision system). The mean relative fluorescence intensities were obtained by averaging the five values, and were used for comparisons.

\section{Statistical Analysis}

Data are presented as mean \pm SEM and statistical tests were calculated by using GraphPad Prism software (San Diego, Calif., USA). The neurological score, infarct volume and hemispheric swelling data comparison between the $\mathrm{NFAT}^{+/+}$and $\mathrm{NFAT}^{+/-}$ mice were analyzed with the Mann-Whitney test [19]. One-way ANOVA was used in all other measurements.

\section{Results}

\section{NFAT5 ${ }^{+/-}$Mice Displayed More Severe Neurological}

Deficits, Larger Infarct Size, Volume, and Brain

Swelling after MCAO-Induced Cerebral Ischemia

To investigate the role of NFAT5 in cerebral ischemia, NFAT5 knockout mice could be used in an in vivo study. However, due to the embryonic lethality of NFAT5 $5^{--}$ mice, therefore, the $\mathrm{NFAT}^{+/-}$heterozygous mice were used as a model of NFAT5 deficiency. RT-PCR and Western blot results showed that about a half-fold reduction of NFAT5 mRNA and protein expression were observed in heterozygous brains when compared with that of the wild-type mice, respectively (fig. la, b). Next, NFAT5 $5^{+/+}$ and $\mathrm{NFAT}^{+/-}$mice were subjected to $\mathrm{tMCAO}$ to induce ischemia and reperfusion injury. No significant differences were observed between the two genotypes in both $\mathrm{rCBF}$ and body temperature (data not shown), indicating that these animals had similar physiological state before and after tMCAO. However, after tMCAO, more severe neurological deficits were observed in NFAT5 ${ }^{+/-}$mice $(1.62 \pm$ $0.14^{*} ; \mathrm{n}=13, \mathrm{p}<0.05$ by the Mann-Whitney test) when compared with $\mathrm{NFAT}^{+/+}$mice $(1.11 \pm 0.11 ; \mathrm{n}=9)$.

TCC staining analysis showed that the percentage of infarct area in brain slices 2 and 3 was significantly larger in $\mathrm{NFAT}^{+/-}$mice than that in the $\mathrm{NFAT}^{+/+}$mice (ta- 
Fig. 1. Expression of NFAT5 in NFAT5-deficient mouse brains at embryonic day 14.5, and analysis of infarct and swelling volume in brains from adult $\mathrm{NFAT}^{+/+}$and $\mathrm{NFAT}^{+/-}$after tMCAO. a Representative figure showing the mRNA expression level of NFAT5 and histogram showing the complete loss of NFAT5 expression in NFAT $^{-/-}$brains and significantly reduced expression was detected in $\mathrm{NFAT5}^{+/-}$ brains. b Western blot analysis showing the loss of NFAT5 protein expression in NFAT5 $^{-/-}$brains and partial loss of expression in $\mathrm{NFAT}^{+/-}$brains. c Histograms showing the percentage of infarct volume in brain slices $\left(\mathrm{NFAT}^{+/+}, \mathrm{n}=7\right.$; $\mathrm{NFAT}^{+/-}$, $\mathrm{n}=8$ ). $\mathbf{d}$ Histograms showing the percentage of hemispheric swelling after tMCAO $\left(\right.$ NFAT5 $^{+/+}, \mathrm{n}=7$; NFAT5 $^{+/-}, \mathrm{n}=8$ ). $\mathrm{NFAT}^{+/-}$brain displayed a significantly larger infarct volume than $\mathrm{NFAT}^{+/+}$ brain, ${ }^{*} \mathrm{p}<0.03$ Mann-Whitney test. A statistically higher percentage of swelling was also found in the ipsilateral hemisphere of $\mathrm{NFAT}^{+/-}$brain after $\mathrm{tMCAO}$, ** $\mathrm{p}<0.02$ Mann-Whitney test. Data are presented as mean \pm SEM.

\section{RT-PCR analysis}

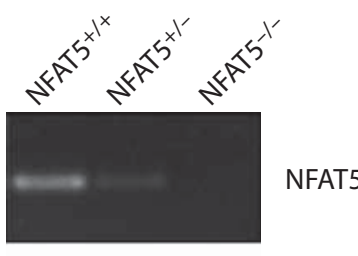

a

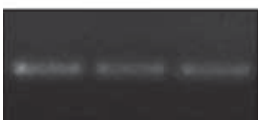

GAPDH

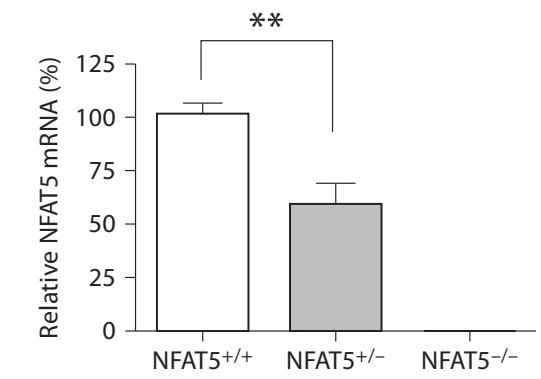

Western blot analysis

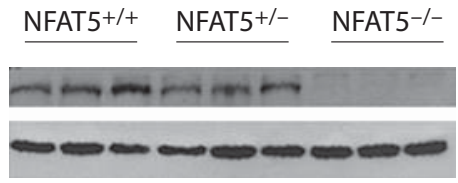

b
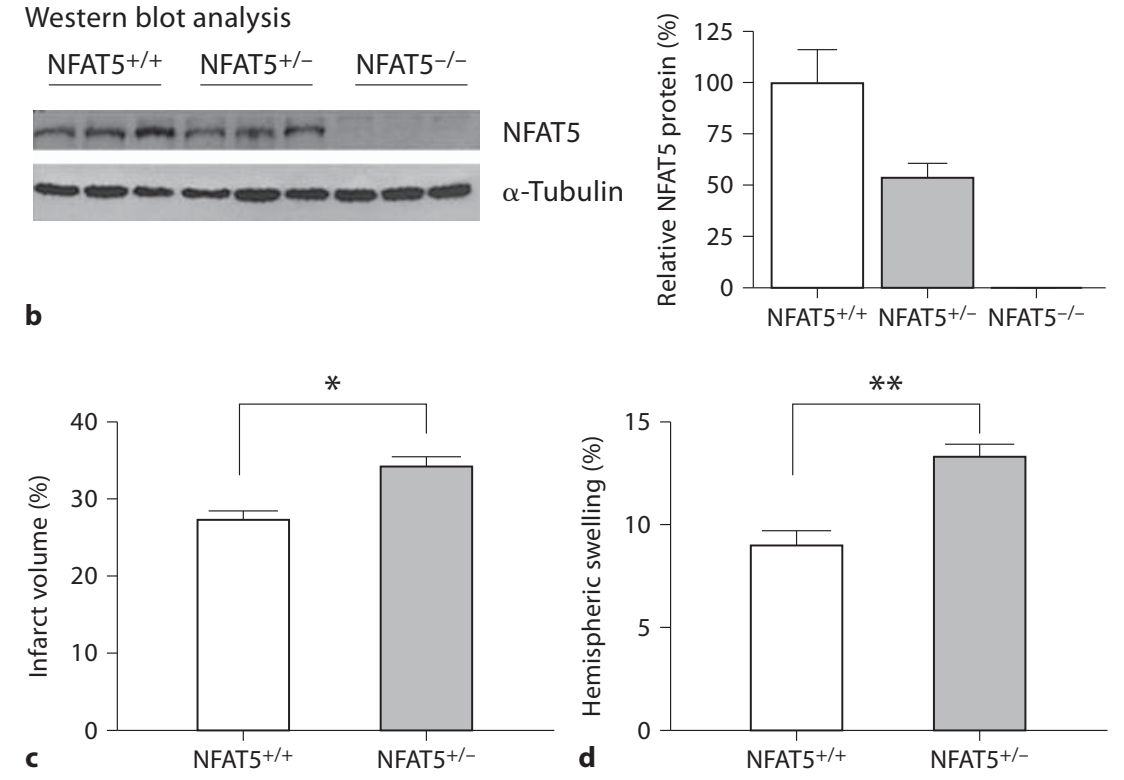

ble 1). Moreover, the percentage of ipsilateral infarct volume (fig. 1c) and hemispheric swelling (fig. 1d) in $\mathrm{NFAT}^{+/-}$brain were also increased significantly.

\section{Blood-Brain Barrier Breakdown Was Exacerbated in $\mathrm{NFAT5}^{+/-}$Brain after Transient MCAO with Downregulation of Occludin Level and Upregulation of Aquaporin-4 Staining in Astrocytic End-Feet}

The increased brain swelling in NFAT5 ${ }^{+/-}$mice after tMCAO suggested the loss of integrity of the blood-brain barrier (BBB). To investigate the integrity of the BBB in $\mathrm{NFAT}^{+/+}$and $\mathrm{NFAT}^{+/-}$mice, the leaky endogenous IgG immunoreactivity was used as a marker of BBB breakdown after $\mathrm{tMCAO}$. In the contralateral hemispheres of both $\mathrm{NFAT}^{+/+}$and $\mathrm{NFAT5}^{+/-}$brains, low background levels of IgG extravasation were observed (fig. 2ai and iii, respectively). Significant increased staining intensities were observed in the ipsilateral side of both $\mathrm{NFAT}^{+/+}$and $\mathrm{NFAT}^{+/-}$brains (fig. 2aii and iv, respectively), with a significantly increased intensity in the ipsilateral side of $\mathrm{NFAT}^{+/-}$cerebral vessels, suggesting that BBB leakage was more severe in $\mathrm{NFAT5}^{+-}$brains. In line with $\operatorname{IgG}$ leakage results, occludin, a tight junction protein associating with $\mathrm{BBB}$, was also downregulated in ipsilateral cerebral vessels of $\mathrm{NFAT5}^{+/-}$brains after tMCAO (data not shown). This indicated that the NFAT $5^{+/}$mice were more susceptible to BBB breakdown after tMCAO.

In a previous study, it was shown that transgenic mice with over-expression of endothelial-1 in astrocytes displayed more severe neurological deficits and edema formation with increased aquaporin-4 (AQP-4) accumulation [19]. To examine whether the increased hemispheric swell- 
Table 1. Percentage of infarct area in ischemic brain slices

\begin{tabular}{|c|c|c|c|c|c|c|}
\hline & \multirow[t]{2}{*}{$\mathrm{n}$} & \multicolumn{5}{|c|}{ Brain slice No. } \\
\hline & & 1 & 2 & 3 & 4 & 5 \\
\hline NFAT5 $^{+/+}$ & 7 & $12.7 \pm 3.7$ & $49.7 \pm 1.6$ & $41.2 \pm 2.4$ & $14.3 \pm 4.0$ & $-2.3 \pm 1.1$ \\
\hline NFAT5 $^{+/-}$ & 8 & $18.4 \pm 6.6$ & $58.1 \pm 3.0^{*}$ & $49.9 \pm 3.5^{* *}$ & $19.8 \pm 3.2$ & $-0.2 \pm 0.5$ \\
\hline
\end{tabular}

Data expressed as mean \pm SEM. ${ }^{*} \mathrm{p}<0.04$ and ${ }^{* *} \mathrm{p}<0.03$, Mann-Whitney test. ing in $\mathrm{NFAT}^{+/-}$mice after tMCAO also associated with AQP-4 expression in astrocytic end-feet. Cellular localization of AQP-4, a water channel protein responsible for modulating water transport in the brain [25], was determined by immunocytochemistry. In the contralateral side of both $\mathrm{NFAT5}^{+/+}$and NFAT5 ${ }^{+-}$brains, AQP-4 staining was localized in astrocytic end-feet, which were in contact with cerebral vessels, thereby displaying their outline (fig. 2bi and ii). The immunoreactivity of AQP-4 was nearly abolished in the ischemic core in both $\mathrm{NFAT5}^{+/+}$and $\mathrm{NFAT}^{+/-}$brains (fig. 2biii and vi, respectively). Near the ipsilateral areas, AQP-4 staining around the cerebral vessels was more diffused when compared with that in the contralateral side. The outlines of cerebral vessels were not distinct. The AQP-4 staining was much higher in the periinfarct area (fig. 2bii and $\mathrm{v}$, respectively). The intensity of AQP-4 staining in ischemic core was also higher in $\mathrm{NFAT}^{+/-}$brain than that of $\mathrm{NFAT}^{+/+}$brain (fig. 2 biii and vi, respectively). Increased AQP-4 staining was more pronounced and diffuse in the NFAT5 ${ }^{+/-}$swollen astrocytic processes, suggesting that after $\mathrm{MCAO}$, there was an upregulation of AQP-4 in astrocytic end-feet of the NFAT5 ${ }^{+/-}$ brains.

\section{Increased Expression and Nuclear Translocation of}

NFAT5 in Neurons after Transient MCAO

$\mathrm{NFAT}^{+/-}$mice showed an increase of water content after $\mathrm{tMCAO}$, and this implied that the loss of NFAT5 might lead to exacerbation of ischemia-induced osmotic stress in the brains. To determine the possible involvement of NFAT5 in ischemic injury, the sub-cellular localization of NFAT5 was examined in brain sections after tMCAO. ICC results showed that immunoreactivity of NFAT5 was observed in the neurons and was significantly higher in the neurons at the ischemic region (fig. 2cii) when compared with the contralateral side (fig. 2ci), suggesting that NFAT5 took part in the intracellular osmoregulation in neurons during ischemic stroke.

\section{Activation of NFAT5 in Neurons under}

Hypoxia/Ischemia

Activation of NFAT5 leads to increased NFAT5 protein synthesis, nuclear translocation or increased transcriptional activity. To investigate whether NFAT5 activation would also induce the above activities in the neurons under hypoxic/ischemic (H/I) injury, in vitro experiments were performed. Primary cortical neurons were isolated from wild-type embryos at E14.5d and challenged the primary cortical neurons with 3-hour H/I condition. In agreement with previous results [12], Western blot analysis showed that significant upregulation of NFAT protein level was observed in $\mathrm{NFAT}^{+/+}$neurons after 3-hour H/I condition (fig. 3a, b).

To examine the nuclear translocation of NFAT5, the subcellular localization of NFAT5 was determined on the primary cortical neurons from E14.5 d embryos exposed to $\mathrm{H} / \mathrm{I}$ by using immunocytochemistry staining with antibodies specific to NFAT5. Under normal (N) condition, NFAT5 was localized in both cytosol and nucleus (fig. 3cii). The NFAT5 signals were only found in the nuclei after $1 \mathrm{~h}$ (fig. 3 civ, v, vi) or $3 \mathrm{~h}$ (fig. 3 cvii, viii, ix) H/I condition and the intensity of signal was also higher than in $\mathrm{N}$ condition, suggesting that the $\mathrm{H} / \mathrm{I}$ condition insult would induce the expression and nuclear translocation of NFAT5 in neurons.

The transcription factor NFAT5 specifically binds to the ORE that enhances the transcription of its target genes [26]. Therefore, ORE-linked luciferase reporter gene was used to examine the transactivating activity of NFAT5 under H/I condition. For the ORE reporter activity, the construct with luciferase driven by ORE sequence and internal control TK-Ren were co-transfected to neuroblastoma cells (SH-SY5Y). For vector control, pGL3 and TK-Ren were co-transfected to SH-SY5Y. The cotransfected cells were subjected to $\mathrm{H} / \mathrm{I}$ condition for 0 (control), 1 and $3 \mathrm{~h}$, respectively. The luciferase activity was normalized by internal control (TK-Ren). Results showed that the ORE-luciferase activity was significantly 


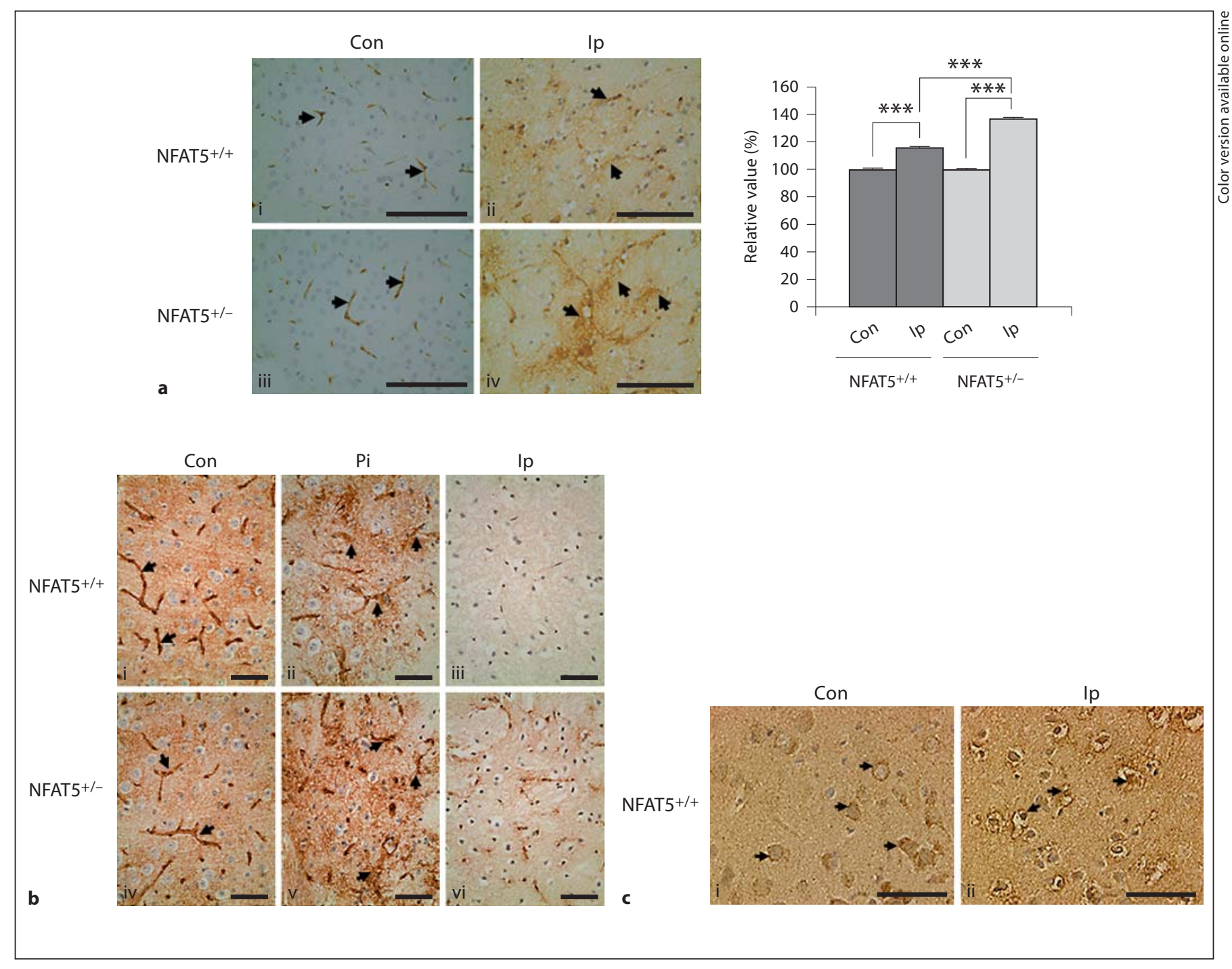

Fig. 2. IgG extravasation, aquaporin-4 expression and cellular localization of NFAT5 in the brain after tMCAO. a Representative micrographs with the IgG staining in NFAT5 ${ }^{+/+}(\mathrm{i}, \mathrm{ii})$ and $\mathrm{NFAT}^{+/-}$(iii, iv) brain section after tMCAO. Similar IgG staining was detected in cerebral blood vessels (black arrows) in the contralateral side of the $\mathrm{NFAT}^{+/+}$and $\mathrm{NFAT}^{+/-}$hemisphere (i and iii). IgG staining was induced in the area of ischemic core of the NFAT5 ${ }^{+/+}$and $\mathrm{NFAT}^{+/-}$ipsilateral hemisphere (ii and iv). Increased IgG leakage (black arrows) in this area was detected in the $\mathrm{NFAT5}^{+/-}$ipsilateral hemisphere (iv) compared to the $\mathrm{NFAT}^{+/+}$ipsilateral hemisphere (ii). Con $=$Contralateral hemisphere; Ip = ipsilateral hemisphere. Scale bar $=100 \mu \mathrm{m} . \mathrm{n}=5$. The histogram on the right shows the quantification of the relative IgG staining intensities in the brain sections; ${ }^{* *} \mathrm{p}<0.01 \mathrm{Mann}$ Whitney test. b Representative micrographs showing the immunostaining of aquaporin-4 (AQP-4) in $\mathrm{NFAT}^{+/+}$(i-iii) and
$\mathrm{NFAT5}^{+/-}$(iv-vi) brain after tMCAO. Contralateral hemispheres of NFAT5 ${ }^{+/+}$brain (i) and $\mathrm{NFAT}^{+/-}$brain (iv) show low level of AQP-4 expression in astrocytic end-feet in contact with cerebral vessels (black arrows). AQP-4 staining was much higher in the pi area (ii and v; black arrows). AQP-4 staining was nearly abolished in Ip of $\mathrm{NFAT}^{+/+}$, whereas intensity of AQP-4 staining in the similar area shows still strong expression in the $\mathrm{NFAT}^{+/-}$hemisphere (iii and vi). Con = Contralateral hemisphere; Ip = ipsilateral hemisphere; $\mathrm{Pi}=$ peri-infract $(\mathrm{n}=5)$. Scale bar $=100 \mu \mathrm{m}$. c Representative photomicrographs from immunocytochemical analysis using antibody against NFAT5. NFAT5 expression was mainly localized in cytoplasm of neurons in the contralateral side (Con) of wild-type brain (i, black arrows), whereas NFAT5 were found in the nuclei of neurons in the ispilateral side (Ip) of brain after tMCAO (ii, black arrows). $\mathrm{n}=4$. Scale bar $=50 \mu \mathrm{m}$. 


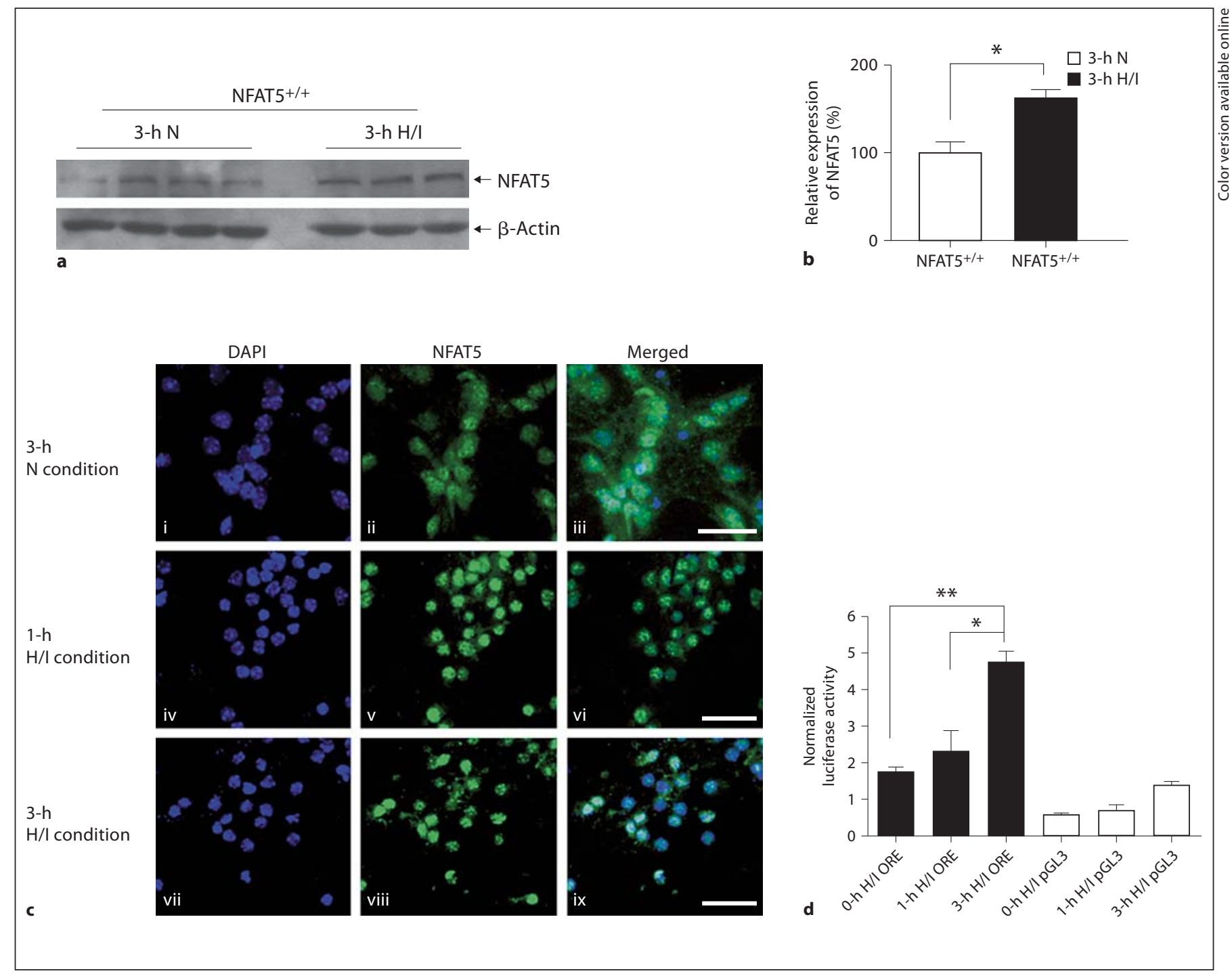

Fig. 3. NFAT5 protein expression level and translocation of NFAT5 and the ORE activity in neurons after $3 \mathrm{~h} \mathrm{H} / \mathrm{I}$ injury. The primary cortical neurons were isolated from $\mathrm{NFAT}^{+/+}$mice at embryonic day 14.5 and challenged to $\mathrm{N}$ or $\mathrm{H} / \mathrm{I}$ for $3 \mathrm{~h}$. a The expression of NFAT5 level was detected by Western blot analysis. b Histogram showing the NFAT5 expression level was significantly increased after 3-hour $\mathrm{H} / \mathrm{I}$ condition. Data are presented as mean \pm SEM. ${ }^{*} \mathrm{p}<0.05$, by one-way ANOVA, $\mathrm{n}=3-4$. The primary cortical neurons were isolated from the $\mathrm{NFAT}^{+/+}$mice at embryonic day 14.5 and subjected to 1 -hour, 3-hour H/I or 3-hour $\mathrm{N}$ condition. Neurons were stained with NFAT5 antibodies

increased about 3-fold in H/I condition (fig. 3d). This indicated that the transactivating activity of NFAT5 was significantly increased during $\mathrm{H} / \mathrm{I}$ treatment. In line with increased protein synthesis and nuclear translocation of NFAT5, a trend of induction of NFAT5 transcriptional
$(1: 4,000)$ (green) (ii, v, viii) to visualize the translocation of NFAT5 in the neurons. DAPI staining (blue) (i, iv, vii) was used for nuclei staining. Merged images were showed in figure $3 \mathrm{c}$ iii, vi, ix. $\mathrm{n}=4$. Scale bar $=100 \mu \mathrm{m}$. c The ORE activity in H/I was measured by the luciferase reporter assay. The neuronal cell line, SH-SY5Y, was transfected with either ORE-Luc (luciferase) or mock (pGL3) constructs. The increase of luciferase activity in ORE-Luc-transfected cells was observed under $\mathrm{H} / \mathrm{I}$ condition and significantly increased in 1- and 3-hour H/I condition. ORE-Luc activity at $0 \mathrm{~h}: 1.74 \pm$ $0.28 ; 1 \mathrm{~h}: 2.32 \pm 0.54 ; 3 \mathrm{~h}: 4.75 \pm 0.27$. Data are presented as mean \pm SEM. ${ }^{*} \mathrm{p}<0.01,{ }^{* *} \mathrm{p}<0.001$ by one-way ANOVA, $\mathrm{n}=3$. 
NFAT5 Deficiency Increased the Severity of Neuronal Death and Apoptotic Cells in the H/I Condition

Previous results demonstrated that, under H/I, there was an increase in transactivation activity in the neuronal cells. Next, we would like to investigate whether NFAT5 is involved in neuronal death in the H/I condition. Cortical neurons from NFAT5-deficient mice at E14.5d were isolated and challenged with 3-hour H/I condition. The media were collected for LDH measurement, which indicated the neuronal cell death. Under normal condition, no significant difference in mortality rate was observed between the NFAT5 ${ }^{+/+}$and NFAT5 $5^{-/-}$ neurons (data not shown). Whereas under the 3-hour $\mathrm{H} / \mathrm{I}$ challenge, the LDH results demonstrated that $\mathrm{NFAT5}^{-/-}$neurons showed a significantly higher cell death than their wild-type counterparts (fig. 4a). This suggested that under H/I condition, NFAT5 deficiency would be detrimental to neuronal cells, and therefore, NFAT5 is important for the survival of neuronal cells under $\mathrm{H} / \mathrm{I}$ condition.

Activation of NFAT5 is important for the survival of neurons against ischemic insult. To examine if NFAT5 deficiency neurons are more susceptible to cell death and undergo apoptosis in H/I condition, apoptosis-related cell death in neurons was investigated by TUNEL staining. Under $\mathrm{N}$ condition, no positive TUNEL staining was observed in both the $\mathrm{NFAT}^{+/+}$or the NFAT5 ${ }^{-/}$primary cortical neurons (data not shown). After the 3-hour H/Itreated neurons, increased TUNEL-positive staining was observed in both the NFAT5 $5^{+/-}$and the NFAT5 ${ }^{-/-}$neurons (fig. 4biii, v and viii, respectively). Qualitative analysis showed that a significantly larger number of $\mathrm{NFAT5}^{-/-}$neurons had undergone apoptosis $\left(\mathrm{NFAT}^{+/+}\right.$, $21.07 \% \pm 2.248 \%$; NFAT5 $^{-/}, 38.31 \% \pm 4.046 \%$; $<<0.05$, Student's t-test) than that in the $\mathrm{NFAT}^{+/+}$neurons (fig. 4c). This result further confirmed that NFAT5 is important in neuronal survival and deficiency of NFAT5 would be harmful to neurons and enhance neuronal apoptosis during the $\mathrm{H} / \mathrm{I}$ insult.

\section{Regulation of Ischemia-Induced Genes by NFAT5}

The activation of NFAT5 is essential in protecting the neurons against $\mathrm{H} / \mathrm{I}$ injury. It is possible that NFAT5 protects the neurons through regulating its transcriptional program against the H/I stress. The mRNA abundance of several genes that are known to be transcriptional downstream targets of NFAT5, namely AR, SMIT, TauT and HSP70 were therefore examined in $\mathrm{NFAT}^{+/+}$, $\mathrm{NFAT}^{+/-}$and $\mathrm{NFAT5}^{-/-}$neurons under 3 -hour N condition or H/I condition by real-time PCR (fig. 5). The AR
mRNA level was not significantly different between genotypes, but a trend of decrease in AR mRNA abundance was detected in NFAT5 $5^{+/}$and $\mathrm{NFAT}^{-/-}$neurons under the $\mathrm{N}$ condition. At 3-hour $\mathrm{H} / \mathrm{I}$ condition, the AR mRNA level was slightly increased while a significant upregulation was observed in NFAT5 ${ }^{-/-}$neurons detected when compared to its N condition (fig. 5a). Similarly, no significant difference of the HSP70 mRNA level was detected in $\mathrm{NFAT5}^{+/+}$, $\mathrm{NFAT}^{+/-}$and $\mathrm{NFAT}^{-/-}$neurons under $\mathrm{N}$ condition, but a significantly increased HSP70 mRNA level was observed in NFAT5 ${ }^{-/}$neurons under $\mathrm{H} / \mathrm{I}$ condition (fig. 5b). In addition, the SMIT mRNA level was significantly downregulated in $\mathrm{NFAT}^{+/-}$and $\mathrm{NFAT}^{-/-}$neurons under N condition (fig. 5c). More importantly, a significant increase of SMIT mRNA level was detected in $\mathrm{NFAT}^{+/+}$neurons under $\mathrm{H} / \mathrm{I}$ condition. However, such an induction was not observed in $\mathrm{NFAT5}^{+/-}$and $\mathrm{NFAT5}^{-/-}$neurons. The level of TauT mRNA was significantly reduced in $\mathrm{NFAT}^{+/-}$and $\mathrm{NFAT}^{-/-}$neurons when compared to that of NFAT5 $5^{+/+}$ neurons under the $\mathrm{N}$ condition (fig. $5 \mathrm{~d}$ ). Under H/I condition, TauT mRNA expression was significantly downregulated in $\mathrm{NFAT}^{+/+}$neurons while the level of TauT was not altered in $\mathrm{NFAT}^{+/-}$and $\mathrm{NFAT}^{-/-}$neurons. Comparing the TauT mRNA abundance under H/I condition, the $\mathrm{NFAT}^{+/+}$neurons still showed a higher mRNA level than the NFAT5 ${ }^{+/-}$and $\mathrm{NFAT}^{-/-}$neurons. Generally, there was a trend of decreased expression of the NFAT5 target gene, such as AR and HSP70, and significant decreases of SMIT and TauT expression under $\mathrm{N}$ condition in $\mathrm{NFAT}^{+/-}$and NFAT5 ${ }^{-/-}$neurons. Significant increases of both AR and HSP 70 expression were observed in $\mathrm{NFAT5}^{-/-}$neurons under $\mathrm{H} / \mathrm{I}$ condition. However, it is still not clear whether the induction of these genes is activated through the NFAT5 directly under H/I condition. The TauT mRNA level was decreased under ischemia suggesting that the transcription of TauT may not regulated by NFAT5 under ischemia. According to the present finding, it is likely that the expression of SMIT was regulated by NFAT5 under hypoxic/ischemic injury.

\section{NFAT5-Deficient Neurons Were More Susceptible to}

Oxidative Stress-Induced Neurotoxicity

Stress-induced proteins, AR and HSP70, were upregulated in NFAT5 $5^{-/-}$neurons after 3-hour H/I condition. The intracellular oxidative stress was monitored by measuring the changes in fluorescence resulting from oxidation of intracellular probe DHE. The NFAT5 primary cortical neurons were isolated and challenged 

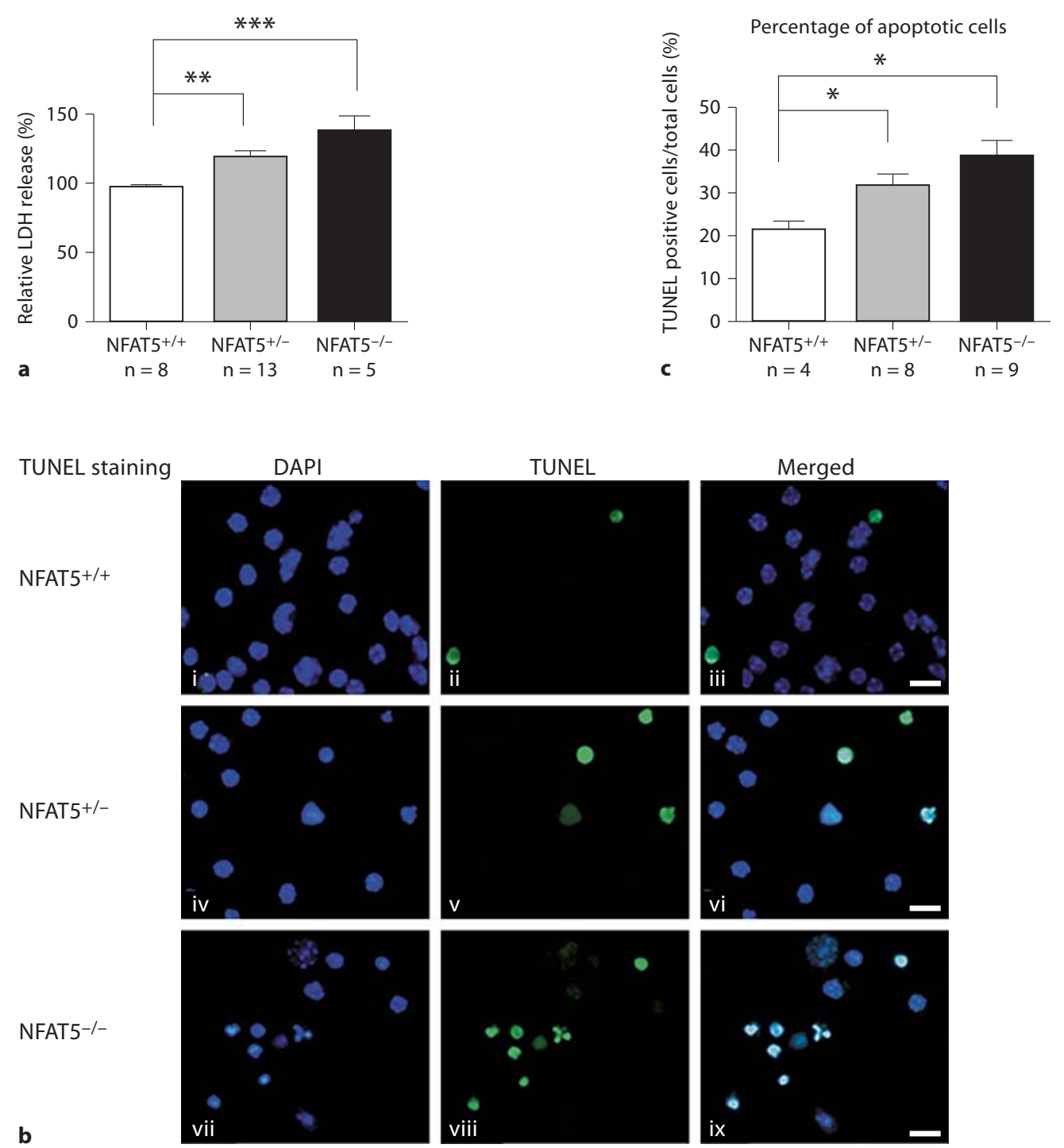

Fig. 4. More LDH release and increased apoptosis were observed in $\mathrm{NFAT}^{-/-}$primary cortical neurons after 3-hour H/I condition. a The cortical neurons were isolated from the brain of 14.5 days $\mathrm{NFAT}^{+/+}, \mathrm{NFAT}^{+/-}, \mathrm{NFAT}^{-/-}$embryonic mice. After 5 days, the neuronal culture was subjected to $3 \mathrm{~h}$ for $\mathrm{H} / \mathrm{I}$, the medium was collected for LDH measurement. The percentage of cell death in the $\mathrm{NFAT}^{+/-}$and NFAT5 ${ }^{-/-}$neurons were significantly higher than in the $\mathrm{NFAT}^{+/+}$neurons under $\mathrm{H} / \mathrm{I}$ condition. Data are presented as mean $\pm \mathrm{SEM}\left(\mathrm{NFAT}^{+/+}, 99.8 \% \pm 2.8 \%\right.$;

with 3-hour H/I condition. The H/I injury caused a rapid and significant accumulation of ROS compared with normoxic condition (data not shown). As shown in figure $6 \mathrm{a}$, a significant increase of ROS was found in
NFAT5 $^{+/-}, 125.8 \% \pm 5.1 \%$; NFAT5 $^{-1-}, 137.2 \% \pm 10.9 \%,{ }^{* *}$ p $<$ 0.01 ; ** $\mathrm{p}<0.001$ by one-way ANOVA). b Photomicrograph showing the TUNEL-positive cells (green) (ii, v, viii). DAPI stains the nucleus (blue) (i, iv, vii). Scale bar $=20 \mu \mathrm{m}$. c Histogram showing the percentage of apoptotic cells in NFAT5 ${ }^{+/+}$, $\mathrm{NFAT5}^{+/-}$and $\mathrm{NFAT5}^{-/-}$neurons (TUNEL-positive cells (apoptotic cells)/DAPI-positive cells (total cells) $\times 100$ ). Data are presented as mean \pm SEM $\left(\mathrm{NFAT5}^{+/+}, 21.07 \% \pm 2.25 \%\right.$; $\mathrm{NFAT5}^{+/-}, 31.62 \% \pm 2.53$; NFAT5 $^{-/}, 38.31 \% \pm 4.05 \%$; ${ }^{*} \mathrm{p}<0.05$, Student's t test).

$\mathrm{NFAT}^{+/-}$and NFAT5 ${ }^{-/-}$neurons when compared to the $\mathrm{NFAT}^{+/+}$neurons $\left({ }^{*} \mathrm{p}<0.05\right.$ and ${ }^{* * *} \mathrm{p}<0.001$, respectively). The result showed that H/I-induced ROS generation is in an NFAT5-dependent manner. To examine 

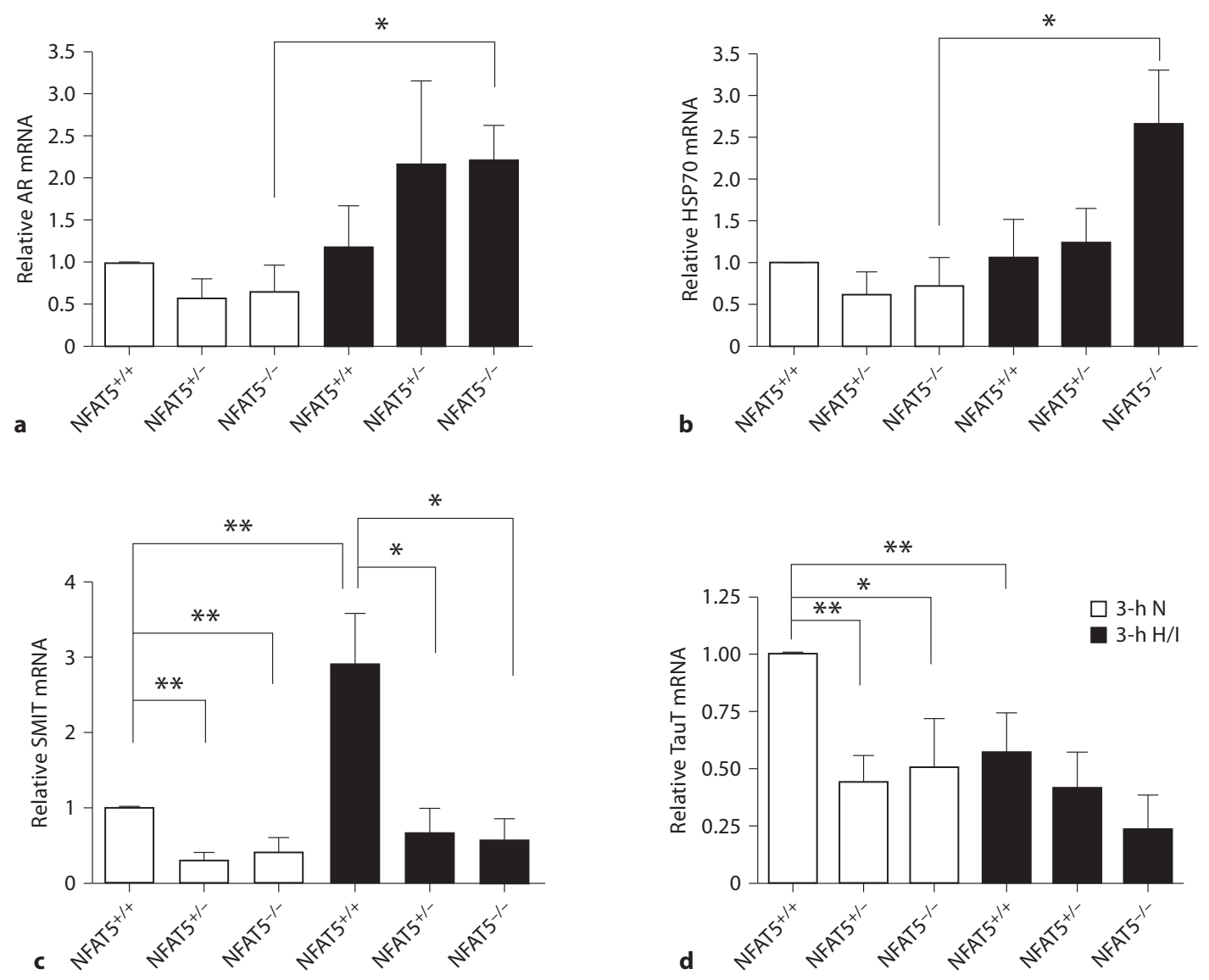

Fig. 5. Real-time PCR analysis of genes downstream to NFAT5 in neurons. The RNA was extracted from primary cortical neurons isolated from brain of E14.5d embryos from NFAT5 $5^{+/+}, \mathrm{NFAT}^{+/-}$ and NFAT5 ${ }^{-/-}$mice and subjected to $3 \mathrm{~h}$ for $\mathrm{N}$ or H/I. Representative histogram showing the relative mRNA abundance of AR (a), HSP70 (b), SMIT (c), and TauT (d) in NFAT5 $5^{+/+}, \mathrm{NFAT}^{+/-}$and $\mathrm{NFAT}^{-/-}$neurons with $\mathrm{N}$ or $\mathrm{H} / \mathrm{I}$ condition. a A significant increase of AR mRNA level was detected in NFAT5 ${ }^{-1-}$ neurons under H/I condition (N vs. H/I, $0.63 \pm 0.33$ vs. $2.18 \pm 0.45$ ). b A significant increase of HSP70 mRNA level was observed in $\mathrm{NFAT}^{-/-}$neurons under $\mathrm{H} / \mathrm{I}$ condition $(\mathrm{N}$ vs. $\mathrm{H} / \mathrm{I}$ condition, 0.72 \pm 0.33 vs. $2.64 \pm 0.65)$. c A significant decrease in SMIT mRNA level was found in $\mathrm{NFAT}^{+/-}$and $\mathrm{NFAT}^{-/-}$neurons under $\mathrm{N}$ con-

the protective role of NFAT5 against oxidative stressinduced neurotoxicity in H/I condition, NFAT5 primary cortical neurons were treated with $100 \mu \mathrm{M} \mathrm{H} \mathrm{H}_{2} \mathrm{O}_{2}$ for $3 \mathrm{~h}$. The media were collected for LDH measurement, which indicates the neuronal cell viability. Figure dition $\left(\mathrm{NFAT5}^{+/+}\right.$vs. $\mathrm{NFAT5}^{+/-}$and $\mathrm{NFAT5}^{-/-}, 1.000 \pm 0.004$ vs. $0.3 \pm 0.1$ and $0.42 \pm 0.18$ ). A significant upregulation of SMIT mRNA level was detected in NFAT5 ${ }^{+/+}$neurons under $\mathrm{H} / \mathrm{I}$ condition $(\mathrm{N}$ vs. $\mathrm{H} / \mathrm{I}$ condition, $1.000 \pm 0.004$ vs. $2.9 \pm 0.7)$. No induction of SMIT mRNA was observed in NFAT5 ${ }^{+/}$and NFAT5 ${ }^{-1-}$ neurons under H/I. d The level of TauT mRNA was significantly downregulated in $\mathrm{NFAT5}^{+/-}$and $\mathrm{NFAT5}^{-/-}$neurons compared to NFAT5 $^{+/+}$neurons under $\mathrm{N}$ condition $\left(\mathrm{NFAT5}^{+/+}\right.$vs. NFAT5 ${ }^{+/-}$ and NFAT5 ${ }^{-1-}, 1.000 \pm 0.004$ vs. $0.43 \pm 0.12$ and $0.51 \pm 0.21$ ). A significant decrease in TauT mRNA level was detected in $\mathrm{NFAT5}^{+/+}$neurons under H/I condition ( $\mathrm{N}$ vs. H/I condition, $1.000 \pm 0.004$ vs. $0.57 \pm 0.17$ ). Data are presented as mean \pm SEM. ${ }^{*} \mathrm{p}<0.05,{ }^{* *} \mathrm{p}<0.01$, by one-way ANOVA, $\mathrm{n}=4$.

$6 \mathrm{~b}$ showed that a significantly higher LDH was released in $\mathrm{NFAT5}^{+/-}$and $\mathrm{NFAT5}^{-/}$neurons than that of $\mathrm{NFAT}^{+/+}$neurons. It implied that NFAT5-deficient neurons were more susceptible to $\mathrm{H}_{2} \mathrm{O}_{2}$-induced neuronal cell death. 

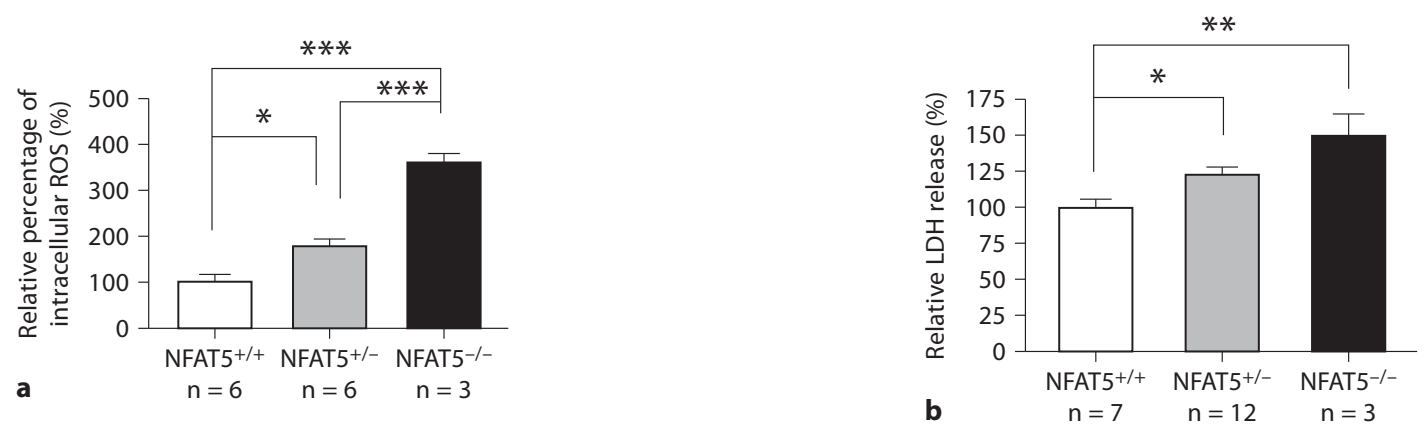

Fig. 6. Increased ROS generation during $3 \mathrm{~h} \mathrm{H} / \mathrm{I}$ condition and more $\mathrm{LDH}$ released were observed after $3 \mathrm{~h} \mathrm{H}_{2} \mathrm{O}_{2}$ treatment in $\mathrm{NFAT}^{-/-}$primary cortical neurons. a The cortical neurons were isolated from the $\mathrm{NFAT5}^{+/+}, \mathrm{NFAT}^{+/-}, \mathrm{NFAT}^{-/-}$mice at embryonic day 14.5. After 5 days, the neuronal culture was subjected to 3-hour H/I condition, the ROS production was measured by the DHE fluorescence intensity. The percentage of ROS generation in the $\mathrm{NFAT5}^{+/-}$and $\mathrm{NFAT5}^{-/-}$neurons was significantly higher than in the $\mathrm{NFAT}^{+/+}$neurons under $\mathrm{H} / \mathrm{I}$ condition. Data are presented as mean \pm SEM $\left(\mathrm{NFAT}^{+/+}, 100 \% \pm 18.15 \%\right.$ NFAT5 $^{+/-}$,

\section{Discussion}

Edema causes a substantial brain swelling and damage [27]. In line with the present study, NFAT5 ${ }^{+/-}$mice showed more severe neurological deficits and more BBB breakdown in their brains associated with increased brain swelling and larger infarct size after tMCAO.

AQP-4, a water channel protein in the brain, is important in brain volume homeostasis, and involves in BBB breakdown, hemispheric swelling and brain edema formation. AQP-4 is highly expressed in astrocytes especially in astrocytic processes that are in contact with capillaries [28]. Under ischemic condition, cerebral swelling correlates with AQP-4 upregulation [29]. Besides, AQP-4 expression in astrocytic end-feet contributes to BBB disruption and brain swelling during brain injury $[19,30]$. In AQP-4 knockout mice, they showed a reduced brain swelling after acute water intoxication and ischemic stroke [31]. Primary astrocytes, which are isolated from AQP-4-deficient mice, show decreased water permeability, suggesting the role of astrocytic AQP-4 in water transport in the brain [32]. The increased AQP-4 expression in the astrocytic end-feet in NFAT5 ${ }^{+/-}$brains after tMCAO contributed to the increase of hemispheric brain swelling and water accumulation, and this is in line with the elevated $\mathrm{BBB}$ disruption and astrocytic hypertrophy in oth-
$177.6 \% \pm 18.4 \%$ NFAT5 $^{-/-}, 356.9 \% \pm 24.01 \%$; ${ }^{*} \mathrm{p}<0.05 ;{ }^{* * *} \mathrm{p}<$ 0.001 by one-way ANOVA). b The cortical neurons were isolated from the NFAT5 $5^{+/+}$, NFAT5 ${ }^{+/-}$, NFAT5 ${ }^{-/-}$mice at embryonic day E14.5. After 5 days, the neuronal culture was subjected to $3 \mathrm{~h}$ for $100 \mu \mathrm{M} \mathrm{H}_{2} \mathrm{O}_{2}$, the medium was collected for LDH measurement. The percentage of cell death in the $\mathrm{NFAT}^{+/-}$and $\mathrm{NFAT}^{-/-}$neurons was significantly higher than in the $\mathrm{NFAT} 5^{+/+}$neurons under $\mathrm{H} / \mathrm{I}$ condition. Data are presented as mean $\pm \mathrm{SEM}\left(\mathrm{NFAT}^{+/+}\right.$, $99.97 \% \pm 5.316 \% ; \mathrm{NFAT5}^{+/-}, 122.6 \% \pm 6.057 \%$ NFAT5 $^{-/-}$, $148.7 \% \pm 15.23 \% ;{ }^{*} \mathrm{p}<0.05 ;{ }^{*} \mathrm{p}<0.01$ by one-way ANOVA). er studies $[19,30]$. However, AQP-4 also plays a role in eliminating excess water in vasogenic edema. AQP-4 is therefore required for the compensatory response to fluid accumulation and edema formation [33]. In the renal system, TonEBP/NFAT5 involves in water homeostasis by regulating the expression of water channel protein AQP1 [34]. In the present study, NFAT5 $5^{+/}$brains showed an increase of water content after tMCAO, the upregulation of AQP-4 expression may responsible for removing excess fluid in the brain parenchyma and restore the water homeostasis back to the normal. NFAT5 may play a neuroprotective role against cerebral edema.

During cerebral ischemia, there is a change of cellular osmolarity in the brain [35]. Neurons undergo intracellular hyperosmotic shock due to the failure of $\mathrm{Na}^{+} / \mathrm{K}^{+}$ATPase pump [35]. This subsequently leads to influx of ions into the cells and increase the intracellular ionic strength, resulting in a rapid swelling and cytotoxic edema formation [35]. The change of intracellular ionic strength triggers the activation of NFAT5 [36], thus increases the compatible osmolytes [38-40] and induces the molecular chaperone [13] to normalize the intracellular volume and the ionic strength, thus to maintain the proper protein folding and optimize the intracellular environment. NFAT5 may function in monitoring and adjusting the intracellular environment by biosynthesis of macromolecules in response to 
the stress [37]. In the in vitro H/I study, the neurons were cultured in isotonic medium. The transcriptional activity of NFAT5, therefore, was due to the intracellular hypertonic shock induced by ischemia rather than the change of external tonicity. Since the downregulation of NFAT5 would lead to a reduced transcription of its target genes $[36,41]$, AR, TauT and SMIT mRNA levels, these downstream targets are possibly regulated by NFAT5.

The SMIT is induced after cerebral ischemia and neuronal injury $[16,42]$. Under H/I injury, SMIT is likely regulated by NFAT5. SMIT mRNA was induced in NFAT5 ${ }^{+/+}$, but not in NFAT5 ${ }^{-/}$, neurons after 3-hour H/I condition, suggesting NFAT5-dependent transcription of SMIT under ischemia. Ischemia-induced influx of $\mathrm{Na}^{+}$and $\mathrm{Ca}^{2+}$ together with water into the neurons results in altering the solute and water transport. This markedly disrupts cellular ionic strength and osmotic homeostasis. Myoinositol (MI) may play an important role to protect the cells against cytotoxicity induced by high intracellular electrolyte concentrations. Previous study showed that veratridine, a neurotoxin that activates voltage-gated $\mathrm{Na}^{+}$ channels, causes cytotoxicity by accumulating $\mathrm{Na}^{+}$ion and also induces SMIT mRNA level in neurons. Induction of MI plays a protective role against veratridine-induced neuronal cytotoxicity [43]. Therefore, it is speculated that disturbance of ionic strength after ischemia induces activation of NFAT5 and increases the transcription of SMIT. SMIT transports MI in exchange of sodium against a high intracellular ionic strength. Since MI plays a role in osmoregulation, it prevents the neuronal swelling from high intracellular $\mathrm{Na}^{+}$and $\mathrm{Ca}^{2+}$ ions. The upregulation of SMIT protects neurons against cellular toxicity induced by high electrolyte concentration.

Hypertonicity induces ROS generation in renal epithelial cells [44]. The failure of $\mathrm{Na}^{+} / \mathrm{K}^{+}$ATPase pump after ischemia leads to increase in intracellular ionic strength. It is plausible that intracellular electrolyte concentration contributes to ROS production. The increase of AR mRNA in NFAT5 ${ }^{-/-}$neurons under H/I condition suggests the AR expression is not regulated by NFAT5dependent transcription. Since the promoter region of the AR gene contains not only the osmotic response element (ORE), but also the activator protein-1 (AP-1) site and two antioxidant response element (ARE)s [45], AR may, therefore, respond to multiple stresses. AR is transcriptionally regulated and activated by a variety of stimuli including ROS generated in ischemia [46-48], AR can be designated as an oxidative stress-inducible protein. This is in line with the increased expression of AR in NFAT5 $^{-/-}$neurons under H/I condition. Also, increased

NFAT5 Protects Brain against Ischemic Injury
AR activity contributes to oxidative stress in the pathogenesis of cerebral ischemia $[15,47]$. The level of AR acts as an indicator of oxidative stress; therefore, the upregulation of AR is associated with a significant increase of ROS in NFAT5 ${ }^{+/-}$and NFAT5 ${ }^{-/}$neurons in H/I condition. This suggests that neuronal cells with NFAT5 deficiency will suffer from greater oxidative damage, and therefore $\mathrm{NFAT5}^{+/-}$and $\mathrm{NFAT5}^{-/-}$neurons showed higher mortality than that of $\mathrm{NFAT5}^{+/+}$in $\mathrm{H}_{2} \mathrm{O}_{2}$-induced neurotoxicity. This may be due to increased AR expression and intracellular ROS as observed in $\mathrm{NFAT5}^{+/-}$and $\mathrm{NFAT}^{-/-}$neurons in H/I injury. The present results are also in agreement with other studies that increased ROS activates the osmoregulatory transcription factor NFAT5/ TonEBP/OREBP $[44,48]$ and deficiency of NFAT5 transcription would exacerbate the neuronal cells under pathological conditions. NFAT5 may protect neurons against oxidative stress under ischemic condition.

HSP70 functions as a molecular chaperone or antiapoptotic molecule which is substantially induced in cells under stresses [49]. It has been shown that HSP70 is regulated by NFAT5 [50]. In the present study, the HSP70 mRNA was induced in neurons under $\mathrm{H} / \mathrm{I}$ condition. When compared with the $\mathrm{NFAT}^{+/+}$neurons, higher HSP70 expressions were observed in $\mathrm{NFAT}^{+/-}$and $\mathrm{NFAT5}^{-/-}$neurons, suggesting that the transcription of HSP70 under H/I is independent of NFAT5 in neuronal cells which is different from other cell types $[51,52]$. Since the stress-induced heat shock factor can also mediate the transcription of HSP70 [53], therefore, the stress-inducible molecular chaperone could be regulated by transcription factor other than NFAT5 under H/I injury. NFAT5 $5^{+/-}$ and NFAT5 ${ }^{-/-}$neurons were more susceptible to ischemic injury with a higher HSP70 expression level which might be resulted from biosynthesis of macromolecules in response to the ischemic stress. It is speculated that increased neuronal damage leads to more molecular chaperones for proper protein folding in NFAT5 $5^{-/}$neurons to cope with neurodegeneration.

The TauT mRNA was downregulated in neurons under in vitro $\mathrm{H} / \mathrm{I}$ condition, which is in agreement with the observation of in vivo experimental stroke model (data not shown). The immunostaining signals of TauT were abolished in the region of ischemic core. During ischemia, cellular swelling may trigger the efflux of amino acids. Studies showed that ischemia-evoked release of amino acid is mediated by $\mathrm{Na}^{+}$-dependent transporters. A depolarization-induced reversal of the $\mathrm{Na}^{+}$-dependent amino acid plasma membrane transporter makes a substantial contribution to the efflux of amino acids [54-56]. 
Ischemia causes a rapid decline in ATP levels and fails the $\mathrm{Na}^{+} / \mathrm{K}^{+}$pump. This leads to the increase of $\mathrm{K}^{+}$extracellularly and decrease of $\mathrm{Na}^{+}$, the cells become depolarized. The reduced $\mathrm{Na}^{+}$gradient would be expected to facilitate ischemia-evoked transporter-mediated release of amino acids. Taurine uptake into cells is also mediated by a $\mathrm{Na}^{+}-$ dependent transporter [57], which operates in a reversed manner when the normal transmembrane ionic gradients is disturbed under H/I conditions. Like in taurine, which has a higher intracellular to extracellular concentration gradient in a normal state, the transporter-mediated efflux can cause a dramatic increase of extracellular taurine during ischemic condition. And this ischemiaevoked taurine release has been suggested to be neuroprotective [58]. The release of taurine, due to an excess of excitatory amino acids, may prevent excitotoxicity in neurons and a higher level of taurine allows the cells to have a greater tolerance to hypoxia [59]. Taurine also enhances $\mathrm{Cl}^{-}$conductivity which reduces cell excitability [60]. Moreover, taurine inhibits the intracellular $\mathrm{Ca}^{2+} \mathrm{up}-$ take elicited by NMDA [61]. Therefore, the increased taurine level is required for a proper homeostasis in neurons upon hyperexcitation. The downregulated-TauT expression in $\mathrm{NFAT5}^{-/-}$neurons under normal and H/I condi- tion may lead to a reduced TauT-mediated taurine efflux and to more susceptibility to $\mathrm{H} / \mathrm{I}$ injury.

In conclusion, $\mathrm{NFAT}^{+/-}$and $\mathrm{NFAT}^{-/-}$neurons showed more severe damages under $\mathrm{H} / \mathrm{I}$ condition resulting from the downregulation of neuroprotective genes (SMIT and TauT) and upregulation of cytotoxic gene (AR) transcriptions. Taken together, NFAT5 is not only essential for neuronal adaptation to the hypertonic condition but also plays an important role in regulating the transcription of genes that restore the neuronal cells back to a normal environment, and therefore protect the cells from ischemic injury.

\section{Acknowledgement}

This work was supported by the Research Grant Council Grants General Research Fund HKU to Professor S.K. Chung 7504/06M and the Area of Excellence from University Grants Council of Hong Kong on Molecular Neuroscience (AoE/B-15/ $01)$.

\section{Disclosure Statement}

The authors declare no conflict of interest.

\section{References}

$\checkmark 1$ Adrogue HJ, Madias NE: Hypernatremia. N Engl J Med 2000;342:1493-1499.

2 Verbalis JG: Disorders of body water homeostasis. Best Pract Res Clin Endocrinol Metab 2003; 17:471-503.

-3 Lin M, Liu SJ, Lim IT: Disorders of water imbalance. Emerg Med Clin North Am 2005; 23:749-770, ix.

4 Matsuoka Y, Hossmann KA: Brain tissue osmolality after middle cerebral artery occlusion in cats. Exp Neurol 1982;77:599-611.

5 Hatashita S, Hoff JT, Salamat SM: An osmotic gradient in ischemic brain edema. Adv Neurol 1990;52:85-92.

6 Gullans SR, Verbalis JG: Control of brain volume during hyperosmolar and hypoosmolar conditions. Annu Rev Med 1993;44: 289-301.

7 Law RO: Regulation of mammalian brain cell volume. J Exp Zool 1994;268:90-96.

-8 Strange K: Regulation of solute and water balance and cell volume in the central nervous system. J Am Soc Nephrol 1992;3:1227.

- Ibsen L, Strange K: In situ localization and osmotic regulation of the $\mathrm{Na}(+)$-myo-inositol cotransporter in rat brain. Am J Physiol 1996;271:F877-F885.

-10 Ayus JC, Armstrong DL, Arieff AI: Effects of hypernatraemia in the central nervous sys- tem and its therapy in rats and rabbits. J Physiol 1996;492(Pt 1):243-255.

11 Woo SK, Lee SD, Kwon HM: TonEBP transcriptional activator in the cellular response to increased osmolality. Pflügers Arch 2002; 444:579-585

12 Woo SK, Kwon HM: Adaptation of kidney medulla to hypertonicity: role of the transcription factor TonEBP. Int Rev Cytol 2002; 215:189-202.

$\checkmark 13$ Woo SK, Lee SD, Na KY, Park WK, Kwon HM: TonEBP/NFAT5 stimulates transcription of HSP70 in response to hypertonicity. Mol Cell Biol 2002;22:5753-5760.

14 Matsumori Y, Hong SM, Aoyama K, Fan Y, Kayama T, Sheldon RA, Vexler ZS, Ferriero DM, Weinstein PR, Liu J: Hsp70 overexpression sequesters AIF and reduces neonatal hypoxic/ischemic brain injury. J Cereb Blood Flow Metab 2005;25:899-910.

15 Lo AC, Cheung AK, Hung VK, Yeung CM, He QY, Chiu JF, Chung SS, Chung SK: Deletion of aldose reductase leads to protection against cerebral ischemic injury. J Cereb Blood Flow Metab 2007;27:1496-1509.

16 Yamashita T, Kohmura E, Yamauchi A, Shimada S, Yuguchi T, Sakaki T, Miyai A, Tohyama $\mathrm{M}$, Hayakawa T: Induction of $\mathrm{Na}^{+} /$ myo-inositol cotransporter mRNA after focal cerebral ischemia: evidence for extensive osmotic stress in remote areas. JCereb Blood Flow Metab 1996;16:1203-1210.

17 Barakat L, Wang D, Bordey A: Carrier-mediated uptake and release of taurine from Bergmann glia in rat cerebellar slices. J Physiol 2002;541:753-767.

18 Loyher ML, Mutin M, Woo SK, Kwon HM, Tappaz ML: Transcription factor tonicity-responsive enhancer-binding protein (TonEBP) which transactivates osmoprotective genes is expressed and upregulated following acute systemic hypertonicity in neurons in brain. Neuroscience 2004;124:89104.

19 Mak MC, Lam KM, Chan PK, Lau YB, Tang WH, Yeung PKK, Ko BCB, Chung SMS, Chung SK: Embryonic lethality in mice lacking the nuclear factor of activated $\mathrm{T}$ cells 5 protein due to impaired cardiac development and function. PLoS One 2011; online publication (http://dx.plos.org/10.1371/ journal.pone.0019186).

20 Lo AC, Chen AY, Hung VK, Yaw LP, Fung MK, Ho MC, Tsang MC, Chung SS, Chung SK: Endothelin-1 overexpression leads to further water accumulation and brain edema after middle cerebral artery occlusion via aquaporin 4 expression in astrocytic endfeet. J Cereb Blood Flow Metab 2005;25:9981011. 
-21 Bonventre JV, Huang Z, Taheri MR, O'Leary E, Li E, Moskowitz MA, Sapirstein A: Reduced fertility and postischaemic brain injury in mice deficient in cytosolic phospholipase $A_{2}$. Nature 1997;390:622-625.

22 Endres M, Wang ZQ, Namura S, Waeber C, Moskowitz MA: Ischemic brain injury is mediated by the activation of poly(ADP-ribose) polymerase. J Cereb Blood Flow Metab 1997; 17:1143-1151.

-23 Huang Z, Huang PL, Panahian N, Dalkara T, Fishman MC, Moskowitz MA: Effects of cerebral ischemia in mice deficient in neuronal nitric oxide synthase. Science 1994;265: 1883-1885.

24 Cai Q, Ferraris JD, Burg MB: Greater tolerance of renal medullary cells for a slow increase in osmolality is associated with enhanced expression of HSP70 and other osmoprotective genes. Am J Physiol Renal Physiol 2004;286:F58-F67.

-25 Badaut J, Lasbennes F, Magistretti PJ, Regli L: Aquaporins in brain: distribution, physiology, and pathophysiology. J Cereb Blood Flow Metab 2002;22:367-378.

-26 Ko BC, Lam AK, Kapus A, Fan L, Chung SK, Chung SS: Fyn and p38 signaling are both required for maximal hypertonic activation of the osmotic response element-binding protein/tonicity-responsive enhancer-binding protein (OREBP/TonEBP). J Biol Chem 2002;277:46085-46092.

-27 Ayata C, Ropper AH: Ischaemic brain oedema. J Clin Neurosci 2002;9:113-124.

-28 Nielsen S, Nagelhus EA, Amiry-Moghaddam M, Bourque C, Agre P, Ottersen OP: Specialized membrane domains for water transport in glial cells: high-resolution immunogold cytochemistry of aquaporin-4 in rat brain. J Neurosci 1997;17:171-180.

-29 Taniguchi M, Yamashita T, Kumura E, Tamatani M, Kobayashi A, Yokawa T, Maruno M, Kato A, Ohnishi T, Kohmura E, Tohyama $\mathrm{M}$, Yoshimine T: Induction of aquaporin-4 water channel mRNA after focal cerebral ischemia in rat. Brain Res Mol Brain Res 2000;78:131-137.

-30 Vizuete ML, Venero JL, Vargas C, Ilundain AA, Echevarria M, Machado A, Cano J: Differential upregulation of aquaporin-4 mRNA expression in reactive astrocytes after brain injury: potential role in brain edema. Neurobiol Dis 1999;6:245-258.

- 31 Manley GT, Fujimura M, Ma T, Noshita N, Filiz F, Bollen AW, Chan P, Verkman AS: Aquaporin-4 deletion in mice reduces brain edema after acute water intoxication and ischemic stroke. Nat Med 2000;6:159163.

- 32 Solenov E, Watanabe H, Manley GT, Verkman AS: Sevenfold-reduced osmotic water permeability in primary astrocyte cultures from AQP-4-deficient mice, measured by a fluorescence quenching method. Am J Physiol Cell Physiol 2004;286:C426-C432.

-33 Papadopoulos MC, Manley GT, Krishna S, Verkman AS: Aquaporin-4 facilitates reab- sorption of excess fluid in vasogenic brain edema. FASEB J 2004;18:1291-1293.

- 34 Lanaspa MA, Andres-Hernando A, Li N, Rivard CJ, Cicerchi C, Roncal-Jimenez C, Schrier RW, Berl T: The expression of aquaporin-1 in the medulla of the kidney is dependent on the transcription factor associated with hypertonicity, TonEBP. J Biol Chem 2010;285:31694-31703.

35 Odland RM, Sutton RL: Hyperosmosis of cerebral injury. Neurol Res 1999;21:500-508.

36 Woo SK, Dahl SC, Handler JS, Kwon HM: Bidirectional regulation of tonicity-responsive enhancer binding protein in response to changes in tonicity. Am J Physiol Renal Physiol 2000;278:F1006-F1012.

37 Ho SN: Intracellular water homeostasis and the mammalian cellular osmotic stress response. J Cell Physiol 2006;206:9-15.

- 38 Ko BC, Ruepp B, Bohren KM, Gabbay KH, Chung SS: Identification and characterization of multiple osmotic response sequences in the human aldose reductase gene. J Biol Chem 1997;272:16431-16437.

39 Rim JS, Atta MG, Dahl SC, Berry GT, Handler JS, Kwon HM: Transcription of the sodi$\mathrm{um} / \mathrm{myo}$-inositol cotransporter gene is regulated by multiple tonicity-responsive en hancers spread over 50 kilobase pairs in the 5'-flanking region. J Biol Chem 1998;273: 20615-20621.

-40 Miyakawa H, Rim JS, Handler JS, Kwon HM: Identification of the second tonicity-responsive enhancer for the betaine transporter (BGT1) gene. Biochim Biophys Acta 1999; 1446:359-364.

41 Lopez-Rodriguez C, Antos CL, Shelton JM, Richardson JA, Lin F, Novobrantseva TI, Bronson RT, Igarashi P, Rao A, Olson EN: Loss of NFAT5 results in renal atrophy and lack of tonicity-responsive gene expression. Proc Natl Acad Sci USA 2004;101:23922397.

42 Yamashita T, Shimada S, Yamauchi A, Guo W, Kohmura E, Hayakawa T, Tohyama M: Induction of $\mathrm{Na}^{+} /$myo-inositol co-transporter mRNA after rat cryogenic injury. Brain Res Mol Brain Res 1997;46:236-242.

43 Yamashita T, Yamauchi A, Miyai A, Taniguchi M, Yoshimine T, Tohyama M: Neuroprotective role of $\mathrm{Na}^{+} /$myo-inositol cotransporter against veratridine cytotoxicity. J Neurochem 1999;72:1864-1870.

44 Zhou X, Ferraris JD, Cai Q, Agarwal A, Burg $\mathrm{MB}$ : Increased reactive oxygen species contribute to high $\mathrm{NaCl}$-induced activation of the osmoregulatory transcription factor TonEBP/OREBP. Am J Physiol Renal Physiol 2005;289:F377-F385.

45 Nishinaka T, Yabe-Nishimura C: Transcription factor Nrf2 regulates promoter activity of mouse aldose reductase (AKR1B3) gene. J Pharmacol Sci 2005;97:43-51.

46 Kaiserova K, Srivastava S, Hoetker JD, Awe SO, Tang XL, Cai J, Bhatnagar A: Redox activation of aldose reductase in the ischemic heart. J Biol Chem 2006;281:15110-15120.
47 Chung SS, Ho EC, Lam KS, Chung SK: Contribution of polyol pathway to diabetes-induced oxidative stress. J Am Soc Nephrol 2003; 14:S233-S236.

48 Zhou X, Ferraris JD, Burg MB: Mitochondrial reactive oxygen species contribute to high $\mathrm{NaCl}$-induced activation of the transcription factor TonEBP/OREBP. Am J Physiol Renal Physiol 2006;290:F1169-F1176.

49 Lee JS, Lee JJ, Seo JS: HSP70 deficiency results in activation of c-Jun $\mathrm{N}$-terminal Kinase, extracellular signal-regulated kinase, and caspase- 3 in hyperosmolarity-induced apoptosis. J Biol Chem 2005;280:6634-6641.

50 Lim YS, Lee JS, Huang TQ, Seo JS: Protein kinase $\mathrm{Cmu}$ plays an essential role in hypertonicity-induced heat shock protein $70 \mathrm{ex}$ pression. Exp Mol Med 2008;40:596-606.

51 Navarro P, Chiong M, Volkwein K, Moraga F, Ocaranza MP, Jalil JE, Lim SW, Kim JA, Kwon HM, Lavandero S: Osmotically-induced genes are controlled by the transcription factor TonEBP in cultured cardiomyocytes. Biochem Biophys Res Commun 2008; 372:326-330

52 Heo JI, Lee MS, Kim JH, Lee JS, Kim J, Park JB, Lee JY, Han JA, Kim JI: The role of tonicity responsive enhancer sites in the transcriptional regulation of human hsp70-2 in response to hypertonic stress. Exp Mol Med 2006;38:295-301.

53 Abravaya K, Myers MP, Murphy SP, Morimoto RI: The human heat shock protein hsp70 interacts with HSF, the transcription factor that regulates heat shock gene expression. Genes Dev 1992;6:1153-1164.

54 Nicholls D, Attwell D: The release and uptake of excitatory amino acids. Trends Pharmacol Sci 1990;11:462-468.

55 Phillis JW, Smith-Barbour M, Perkins LM, O'Regan MH: Characterization of glutamate, aspartate, and GABA release from ischemic rat cerebral cortex. Brain Res Bull 1994;34:457-466.

56 Roettger V, Lipton P: Mechanism of glutamate release from rat hippocampal slices during in vitro ischemia. Neuroscience 1996; 75:677-685.

57 Huxtable RJ: Physiological actions of taurine. Physiol Rev 1992;72:101-163.

58 Takahashi M, Billups B, Rossi D, Sarantis M, Hamann M, Attwell D: The role of glutamate transporters in glutamate homeostasis in the brain. J Exp Biol 1997;200:401-409.

59 Schurr A, Rigor BM: The mechanism of neuronal resistance and adaptation to hypoxia. FEBS Lett 1987;224:4-8.

60 Oja SS, Korpi ER, Saransaari P: Modification of chloride flux across brain membranes by inhibitory amino acids in developing and adult mice. Neurochem Res 1990;15:797804

-61 Lehmann A, Hagberg H, Hamberger A: A role for taurine in the maintenance of homeostasis in the central nervous system during hyperexcitation? Neurosci Lett 1984;52: 341-346. 